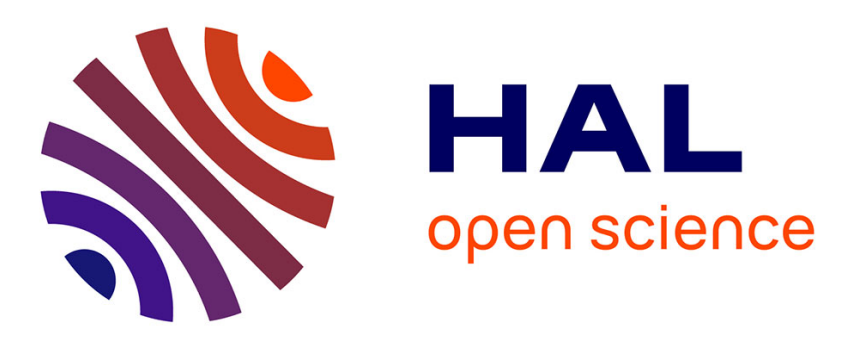

\title{
Thulium-doped silica fibers with enhanced 3H4 level lifetime for fiber lasers and amplifiers
}

Pavel Peterka, Bernard Dussardier, Wilfried Blanc, Ivan Kašík, Pavel Honzatko

\section{- To cite this version:}

Pavel Peterka, Bernard Dussardier, Wilfried Blanc, Ivan Kašík, Pavel Honzatko. Thulium-doped silica fibers with enhanced 3H4 level lifetime for fiber lasers and amplifiers. 3rd International Conference on Photonics 2012 (ICP2012), Oct 2012, Penang, Malaysia. pp.56-60, 10.1109/ICP.2012.6379827 . hal-00779923

\section{HAL Id: hal-00779923 \\ https://hal.science/hal-00779923}

Submitted on 22 Jan 2013

HAL is a multi-disciplinary open access archive for the deposit and dissemination of scientific research documents, whether they are published or not. The documents may come from teaching and research institutions in France or abroad, or from public or private research centers.
L'archive ouverte pluridisciplinaire HAL, est destinée au dépôt et à la diffusion de documents scientifiques de niveau recherche, publiés ou non, émanant des établissements d'enseignement et de recherche français ou étrangers, des laboratoires publics ou privés. 


\title{
Thulium-doped silica fibers with enhanced ${ }^{3} \mathrm{H}_{4}$ level lifetime for fiber lasers and amplifiers
}

\author{
P. Peterka, ${ }^{1}$ B. Dussardier, ${ }^{2}$ W. Blanc, ${ }^{2}$ I. Kasik, ${ }^{1}$ and P. Honzatko ${ }^{1}$ \\ ${ }^{1}$ Institute of Photonics and Electronics AS CR, v.v.i. \\ Chaberská 57, 18251 Prague \\ Czech Republic \\ peterka@ufe.cz \\ ${ }^{2}$ Laboratoire de Physique de la Matière Condensée, Université de Nice Sophia-Antipolis - CNRS, UMR 6622 \\ Parc Valrose - F-06108 Nice \\ France \\ (Invited Paper)
}

\begin{abstract}
Thulium-doped fibers are renowned for their applications in high power fiber lasers at around $2 \mu \mathrm{m}$. It is despite the low quantum conversion efficiency of ${ }^{3} F_{4}$ level in thulium doped silica fibers, which is about $10 \%$ compared to $\sim 100 \%$ quantum conversion efficiency of the ytterbium- and erbium-doped fibers, at around $1 \mu \mathrm{m}$ and $1.5 \mu \mathrm{m}$, respectively. The lower quantum conversion efficiency increases the $2 \mu \mathrm{m}$ laser threshold but has almost no effect on the laser slope efficiency. Indeed, $\mathrm{kW}$-class thulium-doped fiber lasers have been demonstrated recently. Quantum conversion efficiency of the ${ }^{3} \mathrm{H}_{4}$ level in non-modified silica fibers is much lower than that of ${ }^{3} \mathrm{~F}_{4}$ level, only about $2 \%$ and therefore most of the applications of laser transitions originating from ${ }^{3} \mathrm{H}_{4}$ level are hindered by the lack of reliable low-phonon fiber host. We review of our contributions towards the comprehension and improvement of the spectroscopic properties of thulium ions doped into silica. We show potential of the developed thuliumdoped fibers with enhanced ${ }^{3} \mathrm{H}_{4}$ level lifetime for applications in fiber lasers around $810 \mathrm{~nm}$ and in fiber amplifiers for communication S-band $(1460-1530 \mathrm{~nm})$.
\end{abstract}

\section{INTRODUCTION}

Thulium-doped fibers have been widely studied in the past few years. Because of $\mathrm{Tm}^{3+}$ ion rich energy diagram (Fig. 1), lasing action and amplification at multiple infrared and visible wavelengths are allowed. In this paper, we will focus on the ${ }^{3} \mathrm{H}_{4}$ manifold. Thanks to the possible stimulated emission peaking at $1.47 \mu \mathrm{m}\left({ }^{3} \mathrm{H}_{4} \rightarrow{ }^{3} \mathrm{~F}_{4}\right.$, see Fig. 1), discovered by Antipenko et al. [1], one of the most exciting possibilities of $\mathrm{Tm}^{3+}$ ion is amplifying optical signal in the S-band $(1.47-1.52 \mu \mathrm{m})$, in order to increase the available bandwidth for future optical communications. The ${ }^{3} \mathrm{H}_{4}$ level can also decay radiatively by emitting $800 \mathrm{~nm}$ radiation which is of primary importance for high power laser and medical applications. Unfortunately, the upper ${ }^{3} \mathrm{H}_{4}$ level of this transition is very close to the next lower ${ }^{3} \mathrm{H}_{5}$ level so the non-radiative decay (NRD) are likely to happen in high phonon energy glass hosts, causing detrimental gain quenching. Improvement of the $\mathrm{Tm}^{3+}$ spectroscopy was proposed through Tm-Tm [2] and Yb-Tm [3] energy transfers mechanism. In this paper, we discuss on the modification of the local phonon energy around $\mathrm{Tm}^{3+}$ ions to reduce NRD. Then, we present the resulting improvement

The work was supported by CNRS Office of International Relations project No. PICS 5304, Czech Science Foundation project No. P205/11/1840, by the Ministry of Education, Youth and Sports of the Czech Republic, projects No. ME10119 "FILA" and LD11030 (European action COST TD1001), and by the Ministry of Industry and Trade of the Czech Republic, project No. FR-TI4/734. in emission efficiencies for specific applications through numerical modeling. The paper is based on our previous review [4].

\section{LOCAL PHONON INTERACTIONS}

The relevant NRD transition of interest here is from the ${ }^{3} \mathrm{H}_{4}$ level down to the ${ }^{3} \mathrm{H}_{5}$ level. The NRD rate is expressed as [5]:

$$
W_{3}^{n r}=W_{0} \times \exp \left[-\alpha_{V D}\left(\Delta E-2 E_{p}\right)\right]
$$

where $W_{0}$ and $\alpha_{\mathrm{VD}}$ are constants depending on the material, $\Delta E$ is the energy difference between the both levels and $E_{p}$ is the phonon energy of the glass. To improve the quantum efficiency (which depends on the fluorescence lifetime) of the 800 and $1470 \mathrm{~nm}$ emission bands, modifications of $\mathrm{Tm}^{3+}$ ion local environment were investigated by co-doping with selected modifying oxides [6]. $\mathrm{GeO}_{2}$ and $\mathrm{AlO}_{3 / 2}$ have lower maximum phonon energy than silica. As opposite demonstration, high phonon energy $\mathrm{PO}_{5 / 2}$ was also used. To investigate the modification of the local environment, decay curves of the $810 \mathrm{~nm}$ fluorescence from the ${ }^{3} \mathrm{H}_{4}$ level were recorded. All the measured decay curves are nonexponential. This can be attributed to several phenomena and will be discussed in the next paragraph.

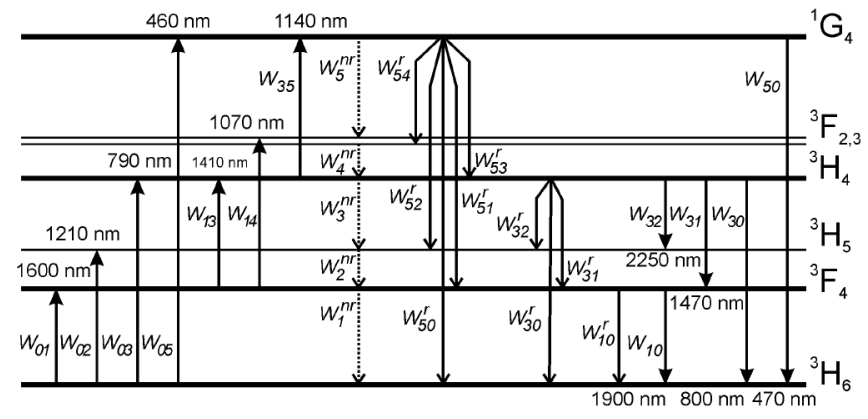

Figure 1. Energy diagram of $\mathrm{Tm}^{3+}$ ion. Parameters are described in the text.

Here, we study the variations of $1 / \mathrm{e}$ lifetimes $(\tau)$ versus concentration of oxides of network modifiers (Al or P) and formers (Ge). The lifetime strongly changes with the composition of the glass host. The most striking results are 
observed within the $\operatorname{Tm}(A l)$ sample series: $\tau$ linearly increases with increasing $\mathrm{AlO}_{3 / 2}$ content, from $14 \mu \mathrm{s}$ in pure silica to $50 \mu \mathrm{s}$ in sample $\operatorname{Tm}(\mathrm{Al})$ containing $17.4 \mathrm{~mol} \%$ of $\mathrm{AlO}_{3 / 2}$. The lifetime was increased about 3.6 times. The lifetime of the $20 \mathrm{~mol} \% \mathrm{GeO}_{2}$ doped fiber $\operatorname{Tm}(\mathrm{Ge})$ was increased up to $28 \mu \mathrm{s}$ whereas that of the $8 \mathrm{~mol} \% \mathrm{PO}_{5 / 2}$ doped fiber $\operatorname{Tm}(P)$ was reduced down to $9 \mu \mathrm{s}$. Aluminum codoping seems the most interesting route among the three tested codopants.

\section{NON-EXPONENTIAL SHAPE OF THE 810-NM EMISSION DECAY CURVES}

In alumina-doped fibers, fluorescence decay curves from the ${ }^{3} \mathrm{H}_{4}$ level were found to be non-exponential. It is thought that $\mathrm{Tm}^{3+}$ ions are inserted in a glass which is characterized by a multitude of different sites available for the RE ion, leading to a multitude of decay constants. This phenomenological model was first proposed by Grinberg et al. and applied to $\mathrm{Cr}^{3+}$ in glasses [7]. This model was applied for the first time to $\mathrm{Tm}^{3+}$-doped glass fibers [8]. In this method, the luminescence decay is given by:

$$
I(t) \approx \sum_{i} A_{i} \exp \left[-t / \tau_{i}\right]
$$

where $A_{i}$ and $\tau_{i}$ are discrete distributions of amplitudes and decay constants (lifetimes), respectively. For the fitting procedure on the $A_{\mathrm{i}}$ series, 125 fixed values for $\tau_{\mathrm{i}}$ were considered, logarithmically spaced from 1 to $1000 \mu \mathrm{s}$. For a given composition (Fig. 2a), we can notice two main distributions of the decay constant. With the alumina concentration, they increase from 6 to $15 \mu \mathrm{s}$ and from 20 to $100 \mu \mathrm{s}$, respectively (Fig. 2b). From the histograms of the amplitude distributions obtained from the fittings, characteristic lifetimes were correlated with those expected for thulium located either in a pure silica or pure $\mathrm{Al}_{2} \mathrm{O}_{3}$ environment. The ${ }^{3} \mathrm{H}_{4}$ lifetime is calculating by using this equation:

$$
1 / \tau=1 / \tau_{\text {rad }}+W_{3}^{n r}
$$

where $\tau_{\text {rad }}$ corresponds to the radiative lifetime which is given to be $670 \mu \mathrm{s}$ in silica [9]. $W_{0}$ and $\alpha$ were estimated for different oxide glasses [5], and [10]. The energy difference $\Delta E$ was estimated by measuring the absorption spectrum of the fibers. When $\mathrm{Al}$ concentration varies, this value is almost constant around $3700 \mathrm{~cm}^{-1}$ [5]. With these considerations, the ${ }^{3} \mathrm{H}_{4}$ expected lifetime can be calculated. In the case of silica glass, $\tau_{\text {silica }}=6 \mu$ s and for a pure $\mathrm{Al}_{2} \mathrm{O}_{3}$ environment, $\tau_{\text {alumina }}=110 \mu \mathrm{s}$. Both values agree with those obtained from the fitting procedure. The distribution of decay constant around $10 \mu \mathrm{s}$ corresponds to $\mathrm{Tm}^{3+}$ ions located in almost pure silica environment whereas the second distribution is attributed to $\mathrm{Tm}^{3+}$ located in $\mathrm{Al}_{2} \mathrm{O}_{3}$ rich sites. This result shows that the global efficiency is increased by increasing the $\mathrm{Al}$ concentration in TDFAs. However concentrations above 20 at $\%$ would cause excess loss and glass stability problems in silica.

\section{MODELING OF TM-DOPED SILICA-FIBER DEVICES}

Numerical models are useful tools for investigating thuliumdoped fiber devices, predicting their performance and optimization of their parameters. We have developed comprehensive, spectrally and spatially resolved numerical model that is based on simultaneous solution of the laser rate equations and propagation equations that describe evolution of the optical power along the fiber.
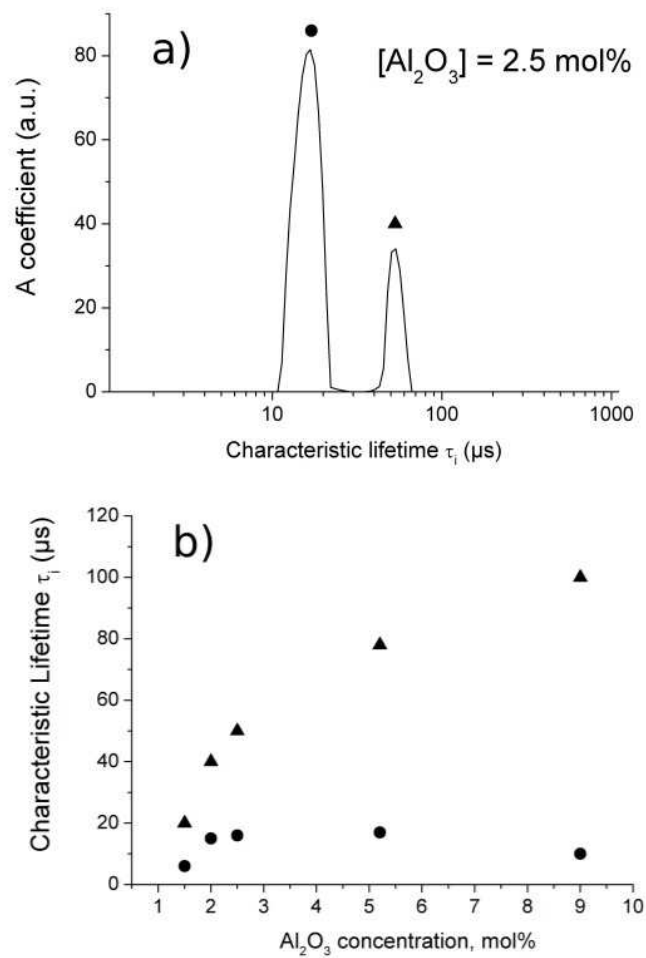

Figure 2. a) Histogram of the recovered amplitude distributions obtained for silica-based $\mathrm{Tm}^{3+}$-doped fibers. b) variations of the short (circle) and long (triangle) characteristic lifetimes vs. $\mathrm{Al}_{2} \mathrm{O}_{3}$ concentration.

The rate equations for the relevant energy levels can be written according to the energy level diagram in Fig. 1 as follows:

$$
\begin{aligned}
\frac{d n_{1}}{d t}= & n_{0}\left(W_{01}+W_{02}\right)-n_{1}\left(W_{10}+W_{13}+W_{14}+W_{1}^{n r}+W_{10}^{r}\right)+ \\
& +n_{3}\left(W_{31}+W_{3}^{n r}+W_{32}^{r}+W_{31}^{r}\right)+n_{5}\left(A_{51}^{r}+A_{52}^{r}\right), \\
\frac{d n_{3}}{d t}= & n_{0}\left(W_{03}+W_{04}\right)+n_{1}\left(W_{13}+W_{14}\right)+n_{5}\left(W_{5}^{n r}+W_{54}^{r}+W_{53}^{r}\right)- \\
& -n_{3}\left(W_{35}+W_{31}+W_{30}+W_{3}^{n r}+\sum_{j=0}^{2} W_{3 j}^{r}\right), \\
\frac{d n_{5}}{d t}= & n_{0} W_{05}+n_{3} W_{35}-n_{5}\left(W_{50}+W_{5}^{n r}+\sum_{j=0}^{4} W_{5 j}^{r}\right),
\end{aligned}
$$

while it holds that the sum of population $n_{i}$ on each respective level is equal to the total thulium ion concentration $n_{t}$ in the core. It is assumed that the thulium ions are homogenously distributed and excited in the doped section of radius $b$ in the fiber core of radius $a$ and it holds that $b \leq a$. The transition rates $W_{i j}$ accounts for the stimulated absorption and emission between the respective levels. 
Spontaneous decay processes are described by $W_{i j}^{r}$ and $W_{i}^{n r}$, the radiative and nonradiative decay rates, respectively. The formulae for the transition rates can be found in [11]. In steady state the rate equations become a set of four linear algebraic equations. The propagation of optical power at respective wavelength is governed by the following propagation equation:

$$
\begin{aligned}
\frac{d P^{ \pm}(\lambda)}{d z}= & \pm \Gamma(\lambda) P^{ \pm}(\lambda) \sum_{i j}^{\{10,30,31,50\}}\left(n_{i} \sigma_{i j}(\lambda)-n_{j} \sigma_{j i}(\lambda)\right) \\
& \mp-(\lambda) P^{ \pm}(\lambda)\left(n_{0} \sigma_{02}(\lambda)+n_{0} \sigma_{04}(\lambda)+n_{1} \sigma_{14}(\lambda)+n_{3} \sigma_{35}(\lambda)\right) \\
& \pm \Gamma(\lambda) \sum_{i j}^{\{10,30,31,50\}} 2 h v_{i j} \Delta n_{i} \sigma_{i j}(\lambda) \mp \chi(\lambda) P^{ \pm}(\lambda) .
\end{aligned}
$$

where $h$ is the Planck constant, $P^{ \pm}$are the spectral power densities of the radiation propagating in both directions along the fiber axis and $\sigma_{i j}$ is the respective transition cross section. The cross sections are shown in Fig. 3. The spectral dependence of the cross sections are approximated by a set of Gaussian functions, the respective coefficients can be found in [12]. The overlap factor $\Gamma$ represents the fraction of the transversal field distribution that interacts with the RE ions. The first term in equation (7) describes the amplification and reabsorption of optical signals, the second term represents ground-state absorption and excited state absorption (ESA) in spectral bands with no significant emission, the third term accounts for spontaneous emission and the fourth term stands for background loss $\alpha$ of the fiber. Evolution of optical power in each ASE spectral slot around a wavelength $\lambda$ (typical $1 \mathrm{~nm}$ wide slot is used) is governed by its respective propagation equation. The propagation equations together with the set of the rate equations under steady state conditions are solved simultaneously along the fiber using Runge-Kutta-Gill method of the fourth order. Since the boundary conditions for the counterpropagating partial waves $P^{-}$are not known at the beginning of the fiber, an iterative solution is applied. The above described numerical model was verified by experimental comparisons, [13] and [14].

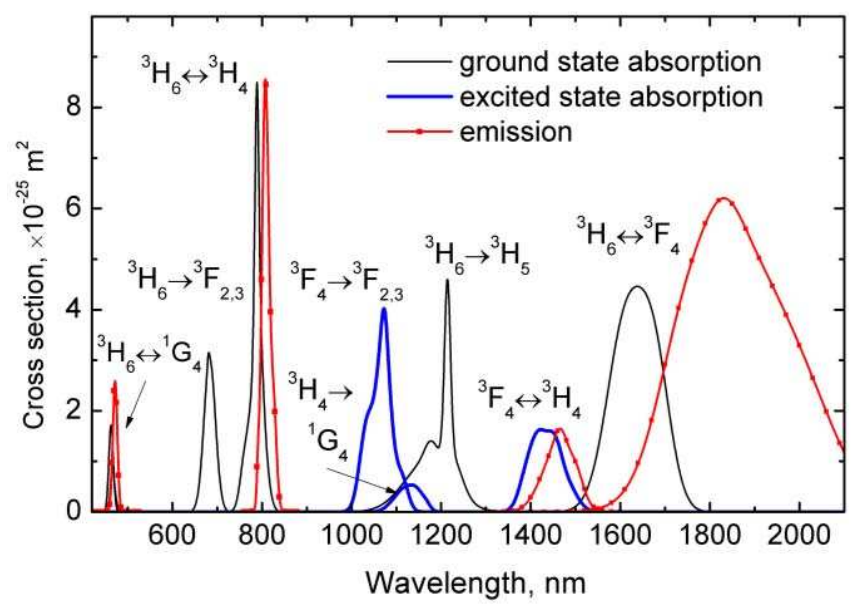

Figure 3. Absorption and emission cross section spectra of thulium.

\section{THULIUM-DOPED FIBER AMPLIFIER AT $1.47 \mu \mathrm{M}$}

The low-loss and single-mode spectral range of the most common single-mode telecommunication fiber spans from about $1260 \mathrm{~nm}$ to $1675 \mathrm{~nm}$. However, this tremendous transmission bandwidth is nowadays used for long-haul transmission only in a restricted portion in the C- (1530$1565 \mathrm{~nm})$ and L-bands (1565-1625 nm), where reliable EDFA are available. The next logical frontier is the S-band $(1460-1530 \mathrm{~nm})$. One of the most promising candidates for amplification in the S-band is the TDFA. Together with EDFA it can substantially increase the bandwidths. An example of a TDFA structure is shown in Fig. 4.

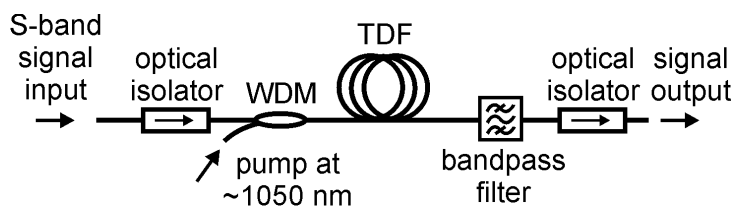

Figure 4. Typical layout of the TDFA.

Two main obstacles have to be solved in order to use the ${ }^{3} \mathrm{H}_{4}$ $\rightarrow{ }^{3} \mathrm{~F}_{4}$ transition in the TDFA. Firstly, the quantum conversion efficiency of the ${ }^{3} \mathrm{H}_{4}$ thulium level should be increased, or in other words, the ${ }^{3} \mathrm{H}_{4}$ fluorescence lifetime should be made longer. One possible solution of the first problem is described above. Secondly, the lifetime of the upper laser level ${ }^{3} \mathrm{H}_{4}$ is shorter than that of the lower level ${ }^{3} \mathrm{~F}_{4}$. Therefore, direct pumping of the ${ }^{3} \mathrm{H}_{4}$ level will hardly constitute the necessary population inversion. The second problem can be solved by using more complex pumping scheme employing gradual upconversion of the thulium ion to the upper laser level. It can be done by a single laser source as shown in Fig. 5a. The disadvantage is the possibility of the ESA ${ }^{3} \mathrm{H}_{4} \rightarrow{ }^{1} \mathrm{G}_{4}$ that results in loosing pump photons. Many dual-wavelength pumping scheme have been also reported as reviewed in [11]. Several results of TDFA performance simulation and of optimization of the TDFA parameters are shown in Fig. 5 and Fig. 6.

The TDFA spectral gain is shown in Fig. $5 \mathrm{~b}$ for different silica fiber hosts represented by the fluorescence lifetime of the ${ }^{3} \mathrm{H}_{4}$ level: $14 \mu$ s of the typical non-modified silica fiber and $45 \mu \mathrm{s}$ of the alumina-doped fiber developed by the authors and $55 \mu$ s of the highly germanium-oxide-doped fiber [15]. Similar value of $58 \mu$ s was also measured in highly alumina-doped fiber [16]. Codirectional pump of 1 $\mathrm{W}$ at $1064 \mathrm{~nm}$ is assumed. Unless otherwise stated, we consider the thulium concentration $n_{t}=1.56 \times 10^{25} \mathrm{~m}^{-3}$, the core diameter $2.6 \mu \mathrm{m}$, numerical aperture $N A=0.3$ and the radiative lifetimes of the levels ${ }^{3} \mathrm{~F}_{4},{ }^{3} \mathrm{H}_{4}$ and ${ }^{1} \mathrm{G}_{4}$ are 3500 , 650 and $860 \mu \mathrm{s}$, respectively. The fluorescence lifetimes of the levels ${ }^{3} \mathrm{~F}_{4},{ }^{3} \mathrm{H}_{4}$ and ${ }^{1} \mathrm{G}_{4}$ are 430,45 and $784 \mu \mathrm{s}$, respectively. For sake of comparisons we set the cross sections of the ${ }^{3} \mathrm{~F}_{4}$ and ${ }^{1} \mathrm{G}_{4}$ levels the same for all fiber host types, although in real fibers they also depend on the host material. We have checked that their values have little effect on the calculated S-band gain compared to the effect of ${ }^{3} \mathrm{H}_{4}$ lifetime. The relevant branching ratios were estimated using Judd-Ofelt theory and were evaluated as follows: $\beta_{54}=0.03$, 
$\beta_{53}=0.11, \beta_{52}=0.30, \beta_{51}=0.06, \beta_{50}=0.50, \beta_{32}=0.03, \beta_{3 l}=0.09$, and $\beta_{30}=0.88$. Zero background loss is assumed. Signal power evolution along the thulium-doped fiber is shown in Fig. 5c for three input pump powers at $1064 \mathrm{~nm}$. The available gain is significantly reduced by the presence of ASE, mainly around $800 \mathrm{~nm}$. Suppression of the ASE, e.g., by cascaded inscription of long-period fiber gratings into the doped fiber or by using thulium-doped photonic crystal fiber with tailored band-gaps, would ameliorate the gain as shown also in Fig. 5.
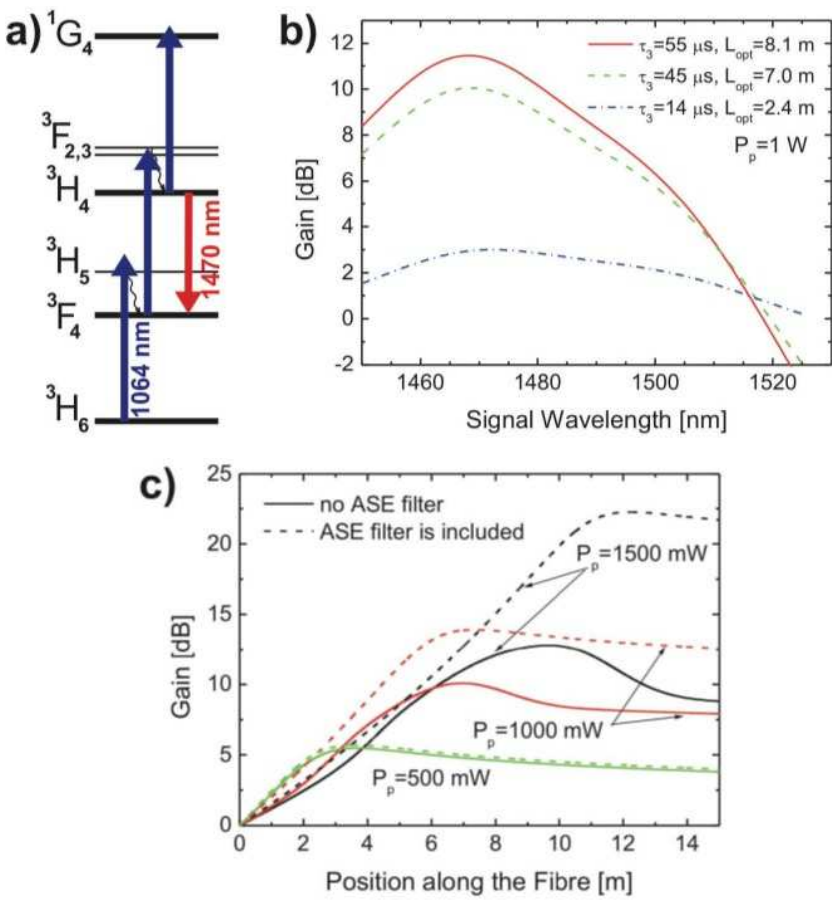

Figure 5. Upconversion pumping of TDFA at around $1050 \mathrm{~nm}$ (a). The effect of glass host composition, mainly manifested by the ${ }^{3} \mathrm{H}_{4}$ level lifetime, on the gain in S-band (b) and optimization of the TDFA length (c).

Optimization of the fiber waveguide parameters is shown in Fig. 6a. Similarly as in the case of the EDFA, the gain gets higher with increasing numerical aperture and narrower core diameter. The effect of distributed filtering out of the ASE around $800 \mathrm{~nm}$ is also shown in the graph. Optimization of the pump wavelength is calculated in Fig. 6b. The optimum pump wavelength shifts towards shorter wavelength with increasing power levels. Shorter wavelength's pump sees lower GSA but at the same time higher first step ESA and consequently the integral value of the population inversion along the fiber is higher.

\section{THULIUM-DOPED FIBER LASER AT $800 \mathrm{~nm}$}

The silica-based fiber lasers around $800 \mathrm{~nm}$ would extend the spectral range covered by high-power fiber lasers. The single-transversal mode, high-power laser source in the 800 $\mathrm{nm}$ spectral band is of interest for a variety of applications. The laser can be used for fiber sensors, instrument testing and for pumping of special types of lasers and amplifiers, e.g. the bismuth-doped lasers. Bismuth-doped fibers pumped around $800 \mathrm{~nm}$ may shift their gain to $1300 \mathrm{~nm}$ telecommunication band, where highly reliable silica-based fiber amplifiers are still unavailable. An efficient fiber laser in $800 \mathrm{~nm}$ spectral region could potentially be used as a replacement for titanium sapphire laser in some applications.
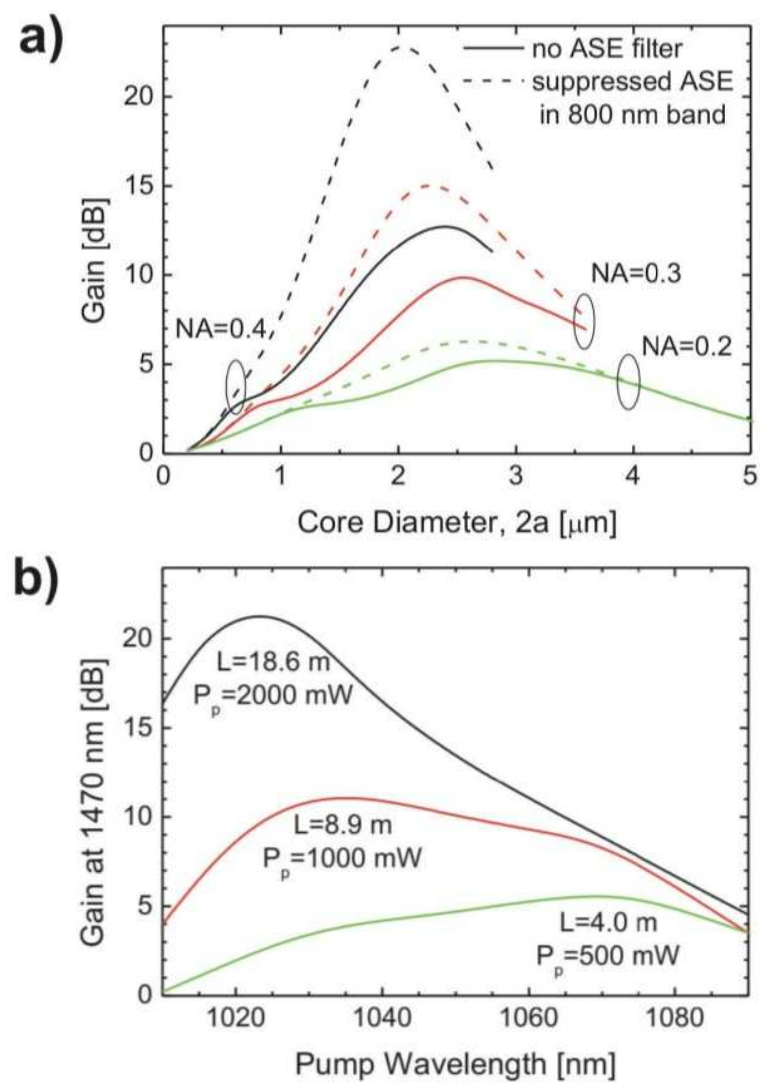

Figure 6. Optimization of the waveguide parameters, namely the NA and core radius (a) and optimization of the pump wavelength (b).

A high-power amplifier in the $800 \mathrm{~nm}$ band would be useful in the optical fiber communications and short-haul free-space communications. Although the laser diodes at this wavelength have been available for a long time, to our knowledge, commercially available single-mode laser diodes are limited to about $200 \mathrm{~mW}$ of output power in diffraction limited beam. It should not be confused with, e.g., laser diode stacks of $\sim \mathrm{kW}$ output power, that are highly multimode with very high $\mathrm{M}^{2}>1000$ factor and low brightness. The amplification and lasing at $800 \mathrm{~nm}$ band has been already investigated using fluoride-based TDFs and output power of up to $2 \mathrm{~W}$ and $37 \%$ slope efficiency was achieved [17]. The output power was limited by the pump damage threshold of the fluoride fiber. Fiber-host reliability problems might be solved by using of silica-based fibers with enhanced ${ }^{3} \mathrm{H}_{4}$ lifetime.

We proposed compact all-silica-fiber setup, example of which is shown in Fig. 7a. The proposed laser utilizes upconversion pumping scheme according to Fig. 7b. We have performed optimization of the waveguide parameters, namely the core radius and $N A$ [12]. The optimum length of the TDF can be determined from the calculated dependence of the laser output on the TDF length as it is shown in Fig. $7 \mathrm{c}$ for the three laser hosts. It can be seen in Fig. 7c that lasing at $810 \mathrm{~nm}$ is hard to achieve with silica-based Tm- 
doped fiber in contrast to the fluoride host materials. However, the lasing might be possible even for silica-based fiber for specific short range of the fiber lengths. Especially when the ${ }^{3} \mathrm{H}_{4}$ lifetime is enhanced, the laser output is very close to the one of ZBLAN host.
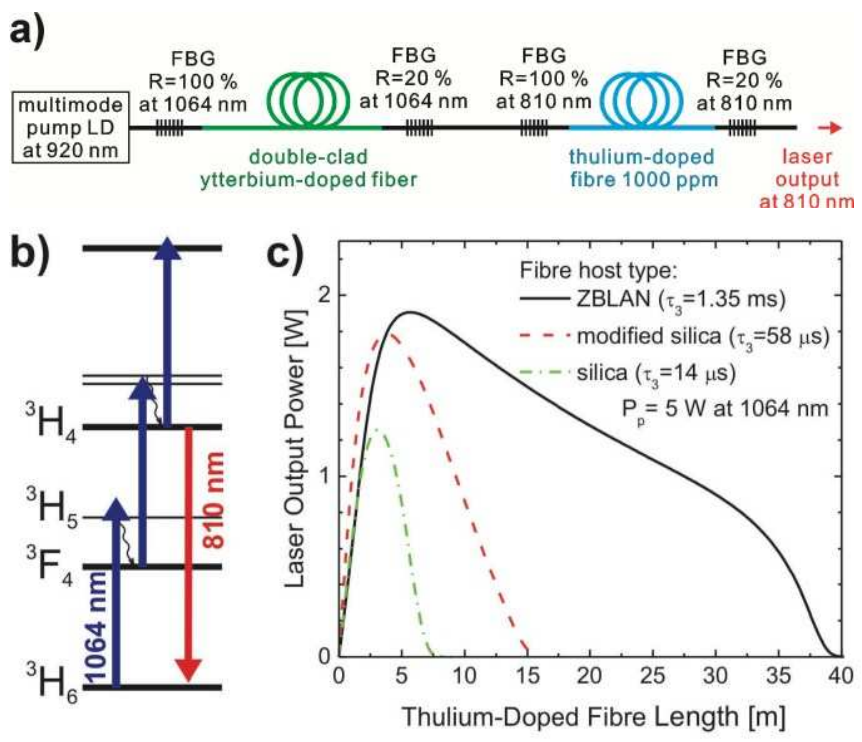

Figure 7. Fiber laser setup in compact all-fiber arrangement (a), single wavelength up-conversion pumping scheme (b), effect of the host material (c). The waveguide parameters used for the parts (c) are: the core diameter of $3.4 \mu \mathrm{m}$ and numerical aperture of 0.2 .

\section{CONCLUSIONS}

Using a comprehensive numerical model we have shown the potential of the developed thulium-doped fibers for applications in fiber amplifiers for S-band telecommunication and for fiber lasers around $810 \mathrm{~nm}$. The gain exceeding $20 \mathrm{~dB}$ of the S-band TDFA could be obtained with optimized fiber waveguiding parameters and optimized pump wavelength. Although the required pump power levels are relatively high, of the orders of Watts, thanks to the progress in ytterbium-doped fiber lasers even these pump powers can provide a cost effective solution. We have shown that efficient lasing at $810 \mathrm{~nm}$ can be achieved using silica-based Tm-doped fiber with enhanced ${ }^{3} \mathrm{H}_{4}$ lifetime for specific ranges of the fiber and laser cavity parameters. Such a fiber laser would broaden the spectral range currently covered by silica-based fiber lasers and it may replace the conventional laser systems in numerous applications.

\section{ACKNOWLEDGMENT}

Authors acknowledge Michèle Ude and Stanislaw Trzesien (LPMC) for the preparation of the preforms and fiber samples.

\section{REFERENCES}

[1] B.M. Antipenko, A.A. Mak, O.B. Raba, K.B. Seiranyan, and T.V. Uvarova, "New lasing transition in the $\mathrm{Tm}^{3+}$ ion," Soviet Journal of Quantum Electronics, vol. 13, pp. 558-560, 1983.

[2] D.A. Simpson, G.W. Baxter, S.F. Collins, W.E.K. Gibbs, W. Blanc, B. Dussardier, and G. Monnom, "Energy transfer up-conversion in $\mathrm{Tm}^{3+}$-doped silica fiber," J. Non-Crystalline Solids, vol. 352, pp. 136141, 2006.

[3] D.A. Simpson, W.E.K. Gibbs, S.F. Collins, W. Blanc, B. Dussardier, G. Monnom, P. Peterka, and G.W. Baxter, "Visible and near infra-red up-conversion in $\mathrm{Tm}^{3+} / \mathrm{Yb}^{3+}$ co-doped silica fibers under $980 \mathrm{~nm}$ excitation," Optics Express, vol. 16, pp. 13781-13799, 2008.

[4] B. Dussardier, W. Blanc, and P. Peterka, "Tailoring of the local environment of active ions in rare-earth- and transition-metal-doped optical fibers, and potential applications," book chapter in Selected topics on optical fiber technology, editors M. Yasin, S. W. Harun, and H. Arof, InTech, Croatia, pp. 97-120, 2012.

[5] J.M.F.Van Dijk and M.F.H. Schuurmans, "On the nonradiative and radiative decay rates and a modified exponential energy gap law for $4 \mathrm{f}-4 \mathrm{f}$ transitions in rare-earth ions," The journal of Chemical Physics. Vol. 78, No 9, pp. 5317-5313, 1983.

[6] B. Faure, W. Blanc, B. Dussardier, and G. Monnom, "Improvement of the $\mathrm{Tm}^{3+}:{ }^{3} \mathrm{H}_{4}$ level lifetime in silica optical fibers by lowering the local phonon energy," J. of Non-Crystalline Solids, vol. 353, pp. 2767-2773, 2007.

[7] M. Grinberg, D.L. Russell, K. Holliday, K. Wisniewski, and C. Koepke, "Continuous function decay analysis of a multisite impurity activated solid," Optics Communications, vol. 156, pp. 409-418, 1998.

[8] W. Blanc, T.L. Sebastian, B. Dussardier, C. Michel, B. Faure, M. Ude, and G. Monnom, "Thulium environment in a silica doped optical fibre," Journal of non-crystalline solids. vol. 354, pp. 435-439, 2008.

[9] B.M. Walsh and N.P. Barnes, "Comparison of Tm:ZBLAN and Tm:silica fiber lasers: Spectroscopy and tunable pulsed laser operation around $1.9 \mu \mathrm{m}, "$ Applied Physics B, vol. 78, pp. 325-333, 2004.

[10] C.B. Layne, W.H. Lowdermilk, and M.J. Weber, "Multiphonon relaxation of rare-earth ions in oxide glasses," Physical Review B, vol. 16, pp.10-21, 1977.

[11] P. Peterka, B. Faure, W. Blanc, M. Karasek, and B. Dussardier, "Theoretical modelling of S-band thulium-doped silica fibre amplifiers," Optical and Quantum Electronics, vol. 36, pp. 201-212, 2004.

[12] P. Peterka, I. Kasik, A. Dhar, B. Dussardier, and W. Blanc, "Theoretical modeling of fiber laser at $810 \mathrm{~nm}$ based on thuliumdoped silica fibers with enhanced ${ }^{3} \mathrm{H}_{4}$ level lifetime," Optics Express, vol. 19, pp. 2773-2781, 2011.

[13] W. Blanc, P. Peterka, B. Faure, B. Dussardier, G. Monnom, I. Kasik, J. Kanka, D. Simpson, and G. Baxter, "Characterization of thuliumdoped silica-based optical fibre for S-band amplifier," SPIE 6180, p. 61800V-1, 2006.

[14] S.R. Lüthi, A.S.L. Gomes, M.L. Sundheimer, B. Dussardier, W. Blanc, and P. Peterka, "Distributed gain in a Tm-doped silica fiber: experiment and modeling," in Proc. CLEO-Europe, paper CJ8-3-FRI, Munchen, Germany, June 17-22, 2007.

[15] B. Cole and M.L. Dennis, "S-band amplification in a thulium doped silicate fiber," Proceedings of Conference on Optical Fiber Communication, Anaheim (CA, USA), March 2001.

[16] P. Peterka, I. Kasik, V. Matejec, W. Blanc, B. Faure, B. Dussardier, G. Monnom, and V. Kubecek, "Thulium-doped silica-based optical fibers for cladding-pumped fiber amplifiers," Optical Materials, vol. 30, pp. 174-176, 2007.

[17] M.L. Dennis, J.W. Dixon, and I. Aggarwal, "High power upconversion lasing at $810 \mathrm{~nm}$ in Tm:ZBLAN fibre," Electronics Letters, vol. 30, pp. 136-13, 1994. 